Case report

\title{
Characterization of hypertrophic osteoarthropathy in an identified skeleton from Évora, Portugal, using combined and comparative morphology and microscopy
}

\author{
Daniela Anselmo ${ }^{a}$, Fernando Capela e Silva $^{\mathrm{a}, \mathrm{b}}$, Teresa Fernandes ${ }^{\mathrm{a}, \mathrm{c}, *}$ \\ a Departamento de Biologia, Escola de Ciências e Tecnologia, Universidade de Évora, Évora 7002-554, Portugal \\ ${ }^{\mathrm{b}}$ Instituto de Ciências Agrárias e Ambientais Mediterrânicas (ICAAM), Universidade de Évora, Évora 7002-554, Portugal \\ c Centro de Investigação em Antropologia e Saúde (CIAS), Universidade de Coimbra, Apartado 3046, Coimbra 3001-401, Portugal
}

\section{A R T I C L E I N F O}

\section{Article history:}

Received 24 July 2015

Received in revised form 28 October 2015

Accepted 4 November 2015

\section{Keywords:}

Hypertrophic osteoarthropathy

Morphology

Light microscopy

Scanning electron microscopy

\begin{abstract}
A B S T R A C T
Hypertrophic osteoarthropathy (HOA) is a bone pathology that can be associated with a number of focal or systemic diseases, particularly those affecting the respiratory system. HOA is characterized by proliferative periostosis of the long bones, especially in their distal and periarticular regions. This report presents a probable case of HOA in the skeleton of an elderly Portuguese male from Évora, Portugal, who died in 1970.

The skeleton was evaluated by morphological, radiological, and histological methods. We found bilateral periosteal proliferation of the tubular bones, remodeling of the phalanges of the feet, and new bone formation on rib visceral surfaces. Bone alterations are more severe on the left tibia and fibula, where lesions display a 'tree bark' appearance, leading to severe thickening of the diaphysis.

Microscopically, we observed deposition of porous woven bone. Our evaluation also considers a differential diagnosis of the lesions, which includes melorheostosis, hypervitaminosis A, fluorosis, thyroid acropachy, tuberculosis, and treponematosis.
\end{abstract}

(c) 2015 Elsevier Inc. All rights reserved.

\section{Introduction}

Hypertrophic osteoarthropathy (HOA) is a bone pathology that can be associated with a number of disease conditions. HOA is found mainly in dogs (Headley et al., 2005; Cetinkaya et al., 2011; Lawler et al., 2015) and humans (Golder and Wolf, 2001; Utine et al., 2008), but has been observed occasionally in various other species (Lenehan and Fetter, 1985; Golder and Wolf, 2001; Mair and Tucker, 2004; Ferguson et al., 2008; Guyot et al., 2011). Although HOA was described in 1868 by Friedenreich (as cited in Kuhn et al., 2007), the exact aetiology remains unknown.

Clinically, there are two forms of HOA, the primary, or idiopathic form, and the secondary, formerly called hyperthrophic pulmonary osteoarthropathy. Only the secondary form is described in dogs. The primary form, also called pachyodermoperiostosis or Touraine-Solente-Golé syndrome, is a rare genetic disease that is

\footnotetext{
* Corresponding author at: Departamento de Biologia, Escola de Ciências e Tecnologia, Universidade de Évora, Évora 7002-554, Portugal.

E-mail addresses: daniela_anselmo@msn.com (D. Anselmo), fcs@uevora.pt (F. Capela e Silva), tmf@uevora.pt (T. Fernandes).
}

inherited in an autosomal fashion (Latos-Bielenska et al., 2007), recently mapped to human chromosome 4q33-q34 and to gene mutations encoding 15-hydroxyprostangladin degradation (Uppal et al., 2008; Yao et al., 2009). This form, usually severe, affects primarily males (Aufderheide and Rodriguez-Martín, 1998), appears around the time of puberty, and its progression is limited to the puberal growth period (Christensen et al., 2013).

Secondary HOA is also called Marie-Bamberger syndrome or hyperthrophic pulmonary osteoarthropathy, emphasizing the pulmonary diseases that represent the major human associates of HOA. Among pulmonary diseases carcinomas are the major cause of HOA. In fact, bronchial carcinoma accounts for $80 \%$ of human HOA, pleural tumors for $10 \%$, other intrathoracic tumors for $5 \%$, and, rarely, Hodgkin's lymphoma is observed (Atkinson et al., 1976; Aufderheide and Rodriguez-Martín, 1998; Resnick and Kransdorf, 2005). Several studies suggest an association between HOA and tuberculosis (Mays and Taylor, 2002; Assis et al., 2011). Other extra-pulmonary conditions that may be associated with HOA include various gastrointestinal, cardiovascular, hepatobiliary, and endocrine disorders (Bazar et al., 2004; Shih, 2004; Vandemergel et al., 2004; Yao et al., 2009). 
HOA is characterized by deposition of periosteal new bone, especially on the tibia, fibula, ulna, and radius. Subchondral bone is unaffected. Clinically, HOA is characterized by digital clubbing and painful swelling of distal limbs (Jajic et al., 2001; Armstrong et al., 2007; Yao et al., 2009). Proliferative periostosis leads to diffuse periosteal ossification and increased circumference of affected bones. Lesions occur more frequently at mid-diaphysis, tapering toward the proximal and distal bone ends. Radiographically, affected bone may suggest having been "pasted" onto the cortex (identified by a distinct radiolucent line between the original and new bone), or may appear to be a dense part of the original cortex where new bone and normal cortex merge imperceptibly (Rothschild and Rothschild, 1998). Primary and secondary forms of HOA can be present in the same skeleton, but usually not on the same bone (Rothschild and Rothschild, 1998).

The goals of this report are to describe morphological, radiological, and histological findings of HOA, to consider the differential diagnosis of the observed lesions, and to discuss possible aetiologies.

\section{Materials and methods}

\subsection{Subject}

The case report (CEIE109) and specimen belong to the Identified Skeletal Collection of Évora, curated at the University of Évora, Portugal. The collection comes from the Cemitério dos Remédios, a city cemetery. The subject of this report was identified as a male, 73 years old, who died in 1970 . The skeleton is very well preserved and complete, as shown in Fig. 1.

The Identified Skeletal Collection of Évora contains 160 skeletons of individuals who died during the 19th and 20th centuries (90 males, 70 females) and upon which research is still in progress. Data that are maintained for each skeleton of this collection come from inhumation registrations and include: age at death (mean age 60 years, range 3-91 years), sex, nationality, occupation, and, in some cases, the cause of death.

\subsection{Macroscopic evaluation}

All the bones were surveyed by naked eye inspection and with a magnifying glass in order to identify and describe lesions.

\subsection{Radiological evaluation}

The bones exhibiting the most severe lesions, the left tibia and fibula, were submitted to radiographic assessment which was performed with a digital system Mammo Diagnost UC system (Philips), at $28 \mathrm{kV}$ and $25 \mathrm{~mA}$, coarse focus, using Kodak Min-R screen film.

\subsection{Histological evaluation}

For histological evaluation, $2-3 \mathrm{~cm}$ samples of the 7th right rib, from the area where lesions are evident, were cut transversally to the long axis with a bone saw [Materials Science (NW) Ltd., Settle, England] and embedded in resin (Technovit ${ }^{\circledR} 9100$, Heraeus Kulzer, Germany) according to the manufacturer's instructions.

The samples were placed in hermetically sealed containers and left to polymerise at $-20^{\circ} \mathrm{C}$ during 5 days. After polymerization $80 \mu \mathrm{m}$ transverse sections were obtained using a saw microtome (Leica 1600, Germany). The undecalcified and unstained sections were observed through a transmitted light microscope Nikon Eclipse 600 (Nikon, Kanagawa, Japan), and digital pictures were collected with a Nikon DN100 camera (Nikon, Kanagawa, Japan).

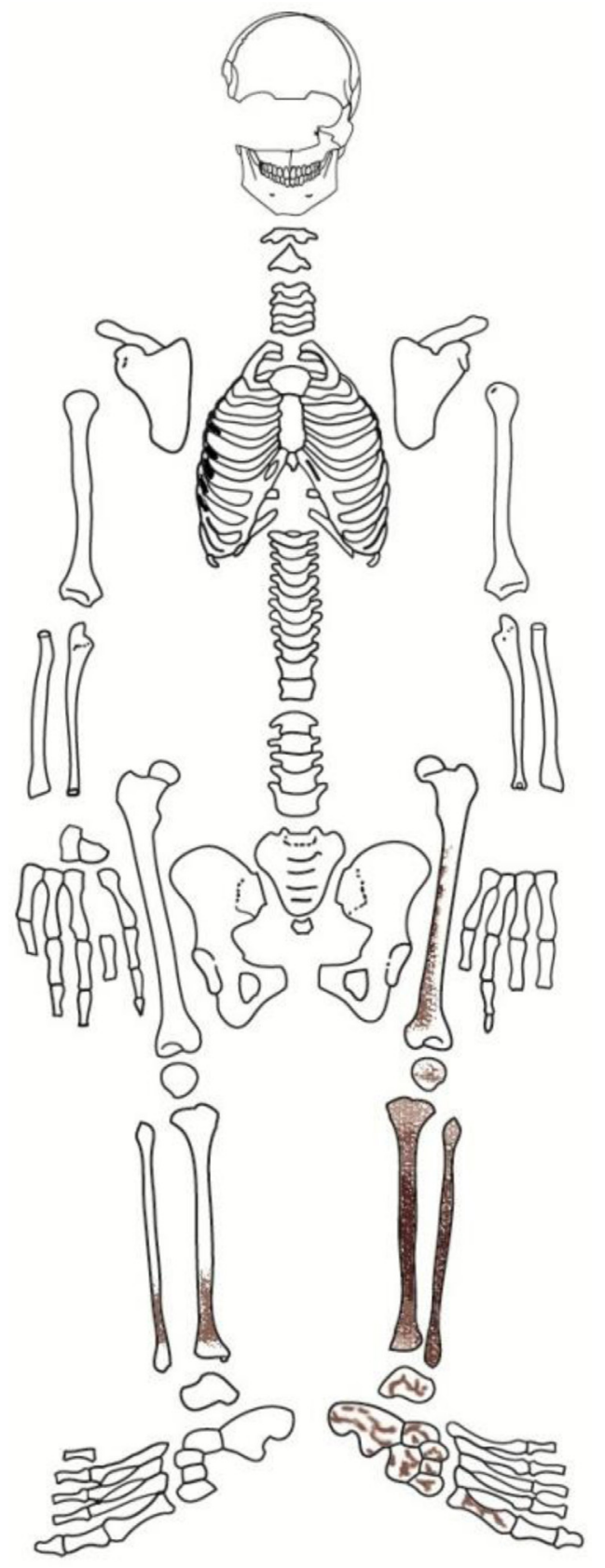

Fig. 1. Drawing indicating the preserved parts of the skeleton. Black shading represents more severe lesions and grey shading more mild lesions. All bones were surveyed visually and with a magnifying glass to identify and describe lesions.

\subsection{Scanning electronic microscopy}

Scanning electron microscopy (Hitachi TM 3000, and SU-70, $30 \mathrm{keV}$ ) was performed to study the affected bone surface morphology of the vertebral extremity of the 7 th right rib. No previous preparation of the rib sample was needed.

\section{Results}

\subsection{Macroscopic and radiological evaluations}

The pathological changes were observed on the right ribs and lower limbs. The fourth through the eighth right ribs display a thin gray layer, not demarcated from the underlying cortex, of woven 


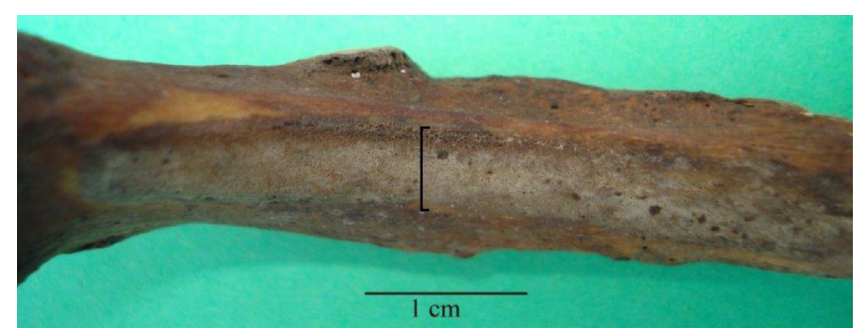

Fig. 2. Close-up of vertebral extremity of the 5th right rib showing new bone deposits on the visceral surface (black line).

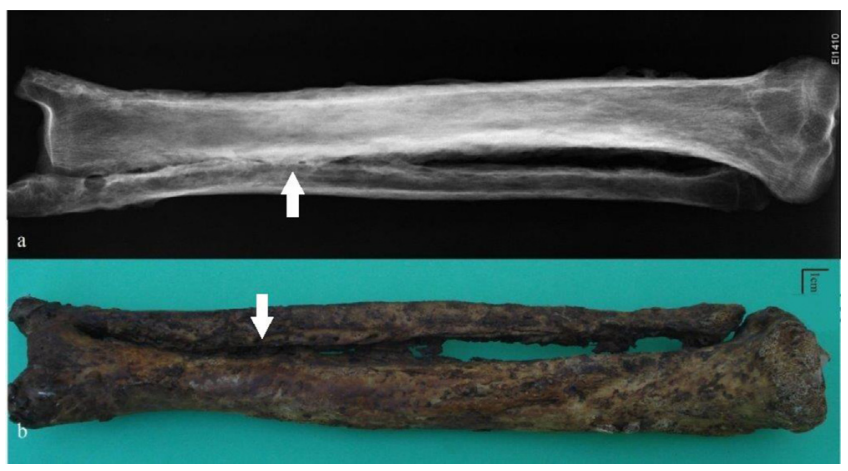

Fig. 3. (a) The radiograph of the left tibia and fibula with periosteal new bone formation. Notice the higher bone density (arrows), especially at mid-diaphysis (posterior view). (b) View of the left tibia and fibula, fused along their distal metaphyses (lateral view).

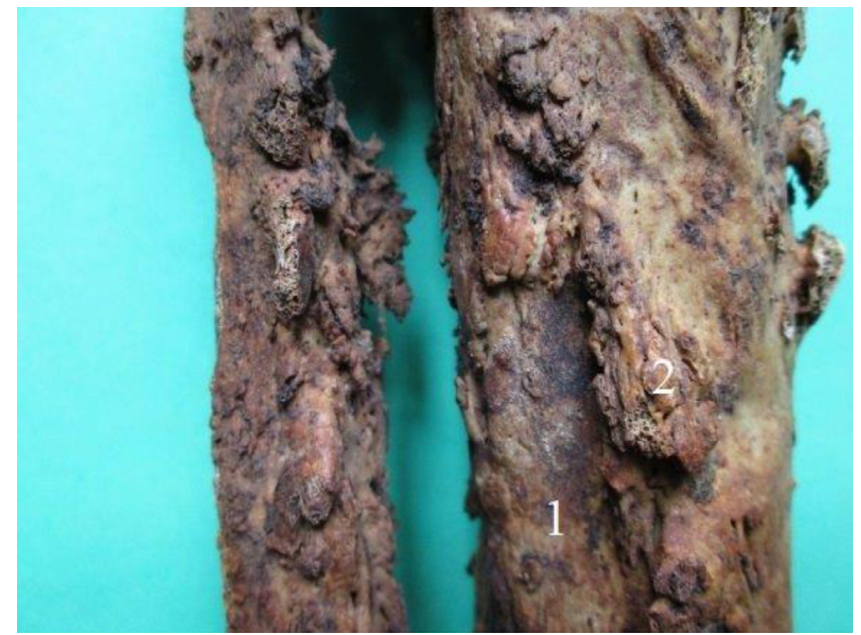

Fig. 4. Close-up of the midshaft of left tibia and fibula, posterior view, illustrating the original (1) and the new bone deposits with a diffuse, irregularly distributed and, in places, nodular periostosis appearance (2).

bone on the visceral surface, mainly near the vertebral extremities, having a rectangular form, and measuring around $2 \mathrm{~cm}$ long (Fig. 2).

The left lower limb (tibia, fibula, femur, and foot) exhibits several severe osseous proliferations with a highly irregular, dense and nodular surface appearance that results in bone thickening. The left tibia and fibula are fused along their distal diaphysis through ossification of the interosseous ligament (Figs. 3 and 4).

The radiographic images (Fig. 3) reveal symmetrical, diffuse and irregular periostosis of the left fibula and tibia, characterized by increased density along the cortical margins of diaphyses and metaphyses. The mid- and distal left tibial diaphysis clearly shows the original cortex, covered by new bone (Fig. 4). Minor but similar changes are present on the left femur, and are more pronounced at the tendinous/ligamentous insertions. At the distal left femoral diaphysis, two types of periosteal reaction are visible: a multilayer thickening due to the presence of new bone with sharply defined edges that is distinguishable from the underlying cortical bone, and a thinner new bone layer covering the original cortex with no visible edge and forming what appears to be an integral part of the cortical surface.

The navicular and calcaneus are the most affected bones of the left foot, showing irregular new bone deposits similar to those of the left tibia and fibula. Navicular lesions involve the entire bone except for the articular surfaces. Calcaneal lesions are most severe at the tuberosity. A trochleo-fibular facet can be observed on the calcaneus, probably due to the fusion of the tibia and fibula.

Distally, the left first metatarsal shows tiny foci of new bone and thickening of the diaphysis. The proximal first phalanx is pathologically altered, with porosity on its posterior diaphysis, probably due to the muscle/tendon insertion as noted by several authors (Ortner, 2003; Christensen et al., 2013). The distal phalanx of the same toe presents new bone deposits at the posterior distal epiphysis, the posteromedial aspect of the proximal diaphysis, and the proximal epiphysis.

Macroscopic observations of the right femur reveal lesions similar to those observed on the left femur, notably on the posterior surface at the mid- and distal diaphysis, although less severely. Right tibial changes were minimal, except for micro- and macroporosity of the distal epiphysis (but which did not affect the joint surface), the striated appearance of remodeled bone on the medial malleolus, and a subtle layer of new bone on the posterior surface at the mid- and distal diaphysis. Radiographically thickened bone is observed along with asymmetric periosteal new bone formation (the lateral surface is thicker than that of the medial surface, especially at the mid-diaphysis). At the area of attachment of the inter-osseous ligament of the right tibial diaphysis, there is a $1 \mathrm{~cm}$ length of periosteal new bone formation.

The right foot has no periosteal lesions, and the remainder of the skeleton reveals degenerative pathologies that are compatible with the subject's age at death, especially multifocal osteophytosis of the vertebral column.

\subsection{Microscopic evaluation}

Histological evaluation of the visceral surface 7 th right rib reveals deposition of woven bone having a spongy character and appearing less organized than the original cortex (Fig. 5). Microporosity is also visible, possibly caused by the same disease process (Fig. 6). The compact bone of the original cortex reveals multifocal areas of lacuna-like irregular spaces. However, the irregular deposition of new bone suggests that these areas probably resulted from increased osteoclastic resorption, not only from the normal process of cortical bone remodeling.

\section{Discussion}

Hypertrophic osteoarthropathy (HOA) is consistent with the location and the type of observed lesions of the lower limbs. Although HOA usually displays bilaterally symmetrical lesions, bilateral symmetry is not universal (Rothschild and Rothschild, 1998; Assis et al., 2011). In other studies, skeletal remains of a young adult woman found at burial site 23 during the exploration of Jaina (Mexico), and now curated at the Physical Anthropology Department of the National Museum of Anthropology of Mexico City (Martinez-Lavin et al., 1994), has a fibula with advanced periosteal new bone formation that was diagnosed as HOA. In a second report, Christensen et al., 2013 described an adult male exhumed at the medieval site of Zalavár in South-West Hungary which has tibial 


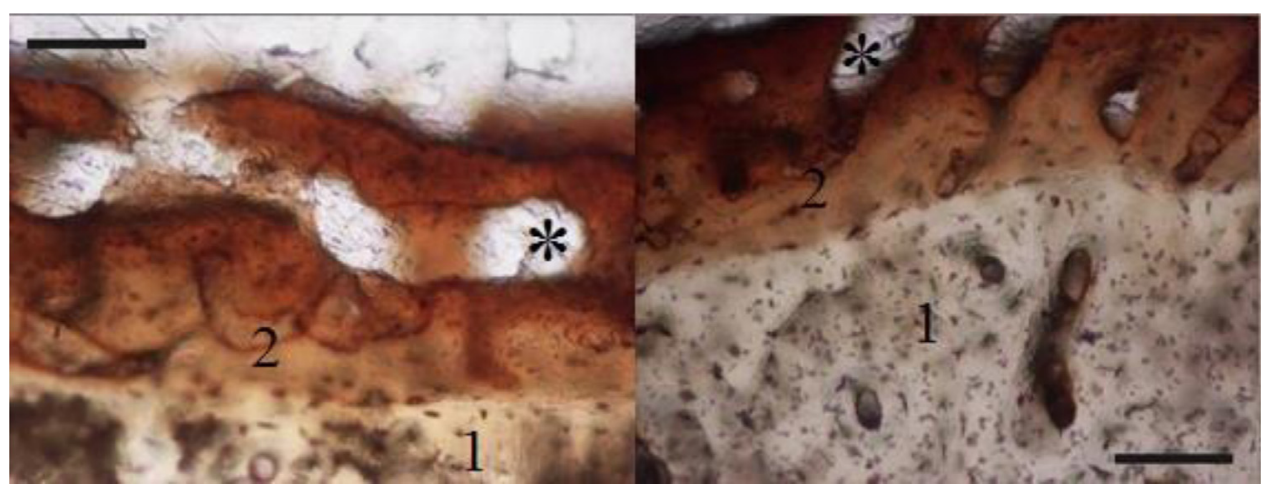

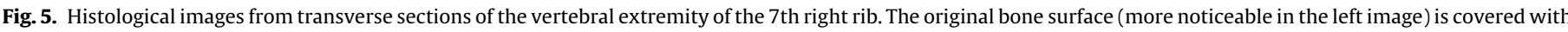

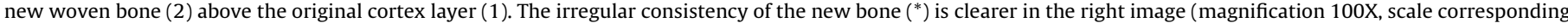
to $100 \mu \mathrm{m})$.

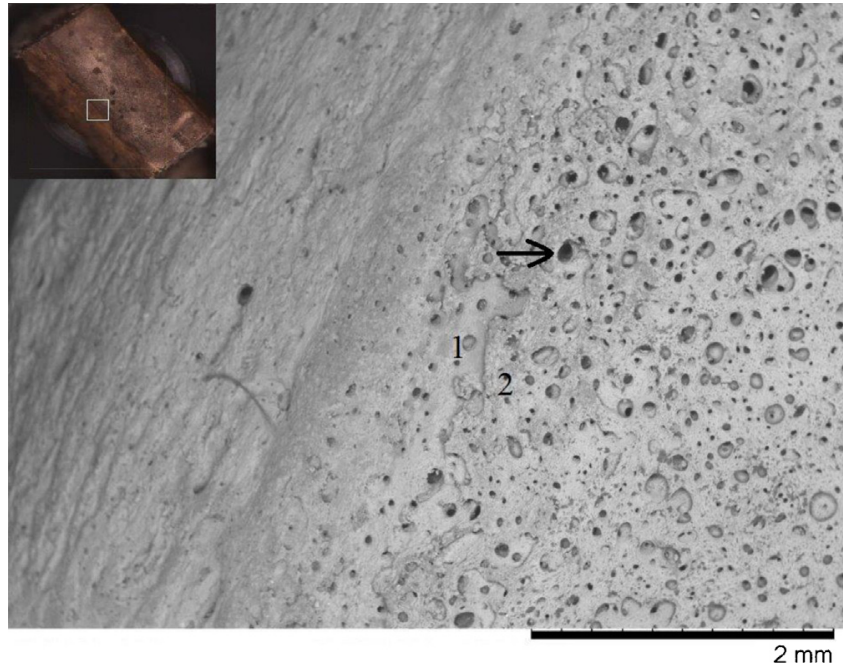

Fig. 6. The smaller image shows the vertebral extremity of the right 7 th rib that was chosen to demonstrate deposits of new bone (2) covering the original cortex (1). Magnified $30 \times$ by SEM, showing focal microporosity (arrow) in the new bone deposits and in the original layer.

and fibular lesions that are morphologically similar to those of our subject, and also was diagnosed with HOA. A third report describes tibiae and fibulae from a 58-year-old woman, IPAZ 6646, that again presents with similar dense and nodular surfaces that were identified as HOA (Ortner, 2003). Recently, González-Reimers et al., 2015 described four bones, presumably belonging to the same individual, which were exhumed from a collective burial cave of the island of El Hierro, in the Canary Archipelago. Remains, dated to $1000 \mathrm{BP}$, show severe periosteal bone proliferations similar to those of the present study. Lastly, archaeological remains of a domestic dog excavated at the Cleveland site, in Ontario, Canada, has remarkably similar lesions affecting the metacarpal bones (von Hunnius, 2009).

The present remains, and the above-described reports, all suggest secondary HOA; the apparent ages of the subjects are not in agreement with a diagnosis of primary HOA. Most of the cases referred to above were observed in younger individuals; however, it must be remembered that this is a recent case, the individual died in 1970, and medical advances, including the use of antibiotics, could explain survival to an advanced age. Our microscopic analysis also supports diagnosis of a chronic disorder affecting the ribs, as reported by other authors (Wakely et al., 1991) and in other bones (von Hunnius, 2009). HOA can be secondarily related to a number of conditions, especially various chronic pulmonary diseases.
Therefore, it is appropriate to consider the differential diagnoses for HOA in the remains considered here.

Melorheostosis (sometimes called Leri's hyperostotic osteopathy) is a developmental skeletal dysplasia that causes linear hyperostosis that closely resembles lesions of HOA. Melorheostosis usually affects only one bone or one limb, and commonly involves the neurocranium and the hip bones (Leri and Joanny, 1992; Freyschmidt, 2001; Subhas et al., 2008; Abdullah et al., 2011). Radiographic images of this disease reveal cortical and endosteal involvement (Graham and Parke, 2005). Thus, we concluded that the specimens we evaluated is insufficiently compatible with melorheostosis.

The distribution of the lesions also enabled exclusion of thyroid acropachy. Individuals with hyperthyroidism may show acropachy and sub-periosteal new bone deposition, but usually the manifestation is also present in bones of the hands and feet (Tran, 2004).

Fluorosis and Hypervitaminosis A are diseases of nutritionrelated metabolism that lead to bone lesions. Both were eliminated from the differential diagnosis, as both affect the axial skeleton (not only the ribs) quite prominently, and either periosteal or endosteal bone as well (Aufderheide and Rodríguez-Martín, 1998), and fluorosis is also characterized by abnormalities of dental enamel and tends to effect cancellous bone more generally.

Treponemal spp. may lead to four different diseases: yaws (Treponema pertenue), pinta (Treponema carateum), bejel (Treponema pallidum endemicum) and syphilis (Treponema pallidum pallidum). In their tertiary stages, all but pinta can produce bone lesions. Syphilis, the most common form in Europe, has typical cranial and facial lesions, for example caries sicca, first described by Virchow in 1858 (as cited in Ortner, 2003), representing the only lesion type that can be considered pathognomonic (e.g. Ortner, 2003; Santos et al., 2013). Although treponemal bone surface changes (gummatous lesions) may resemble those described here, they tend to be scattered, accompanied by focal areas of necrosis, and affect endosteum as well as the medullary cavity. The long bones most affected by treponemal infection are the tibiae and the femora, with the periosteum of the distal diaphysis primarily affected and resembling a fusiform expansion (Aufderheide and Rodriguez-Martín, 1998). Since similar lesions were not found in the subject that we evaluated, we eliminated Treponema ssp. as diagnostic possibilities.

According to numerous reports, HOA may be recognized secondary to tuberculosis. This relationship was evaluated using molecular analysis of osteological remains of a previously published case (Mays and Taylor, 2002; Masson et al., 2013). In the Coimbra Skeletal Identified Collection, housed at Coimbra University, in Portugal, there is a more frequent relationship between tuberculosis and HOA than between other causes of death and HOA (Assis et al., 2011). The Hamman-Todd, Grant and Terry 
collections also suggest a high correlation between HOA and chronic pulmonary diseases (Rothschild and Rothschild, 1998).

The skeletal involvement of tuberculosis infrequently results in substantial subperiosteal bone deposition on the shafts of long and short tubular bones. Skeletal lesions of human tuberculosis more commonly involve the vertebral column, with a tendency for osteolytic lesions (Aufderheide and Rodriguez-Martín, 1998; Roberts and Buikstra, 2003; Pálfi et al., 2012). Some authors (Roberts and Buikstra, 2003) note an increased prevalence of lesions affecting weight-bearing joints, such as the hips and the knees. The specimen we evaluated had no lesions at these sites, and bone changes were not unilateral, as can be found in tuberculosis. Nevertheless, plaques of new bone on the visceral surfaces of the ribs, especially if found in proximity to the vertebral ends and in the middle ribs of the cage (that we did observe), have been indicated as common findings in paleopathological analyses of pulmonary tuberculosis (e.g., Roberts et al., 1994, 1998; Matos and Santos, 2006; Santos and Roberts, 2006).

\section{Conclusion}

As the hospital clinical information has not yet been found, we conclude that the present case can be diagnosed as HOA. However, we have insufficient information to diagnose a probable cause for HOA at this time. We cannot exclude the possibility of pulmonary tuberculosis, or the possibility of one or more co-morbidities, including non-infectious diseases. This study helps to emphasize the usefulness of histology in paleopathological studies (see the review by De Boer et al., 2013), as it allowed for a more detailed discussion of the manifestations of HOA.

\section{Acknowledgments}

This chapter is funded by FEDER Funds through the Operational Programme for Competitiveness Factors - COMPETE and National Funds through FCT - Foundation for Science and Technology under the Strategic Projects PEst-C/AGR/UI0115/2011, PEst-OE/AGR/UI0115/2014 and through the Programa Operacional Regional do Alentejo (InAlentejo) Operation ALENT-07-0262FEDER-001871/Laboratório de Biotecnologia Aplicada e Tecnologias Agro-Ambientais. The funding source played no role in the development of the present work or upon its submission for publication.

The authors greatly appreciate the assistance of: the Veterinary Hospital of Universidade de Évora for production of the X-rays, Évora Hospital for medical information of the individual studied, Registry of Évora and Castelo Branco for the date of birth and birthplace of the individual studied and VWR Portugal for scanning electronic microscope utilization and André Anselmo for the image treatment.

\section{References}

Abdullah, S., Pang, G.M., Mohamed-Haflah, N.H., Sapuan, J., 2011. Melorheostosis of the ulna. J. Chin. Med. Assoc. 74, 469-472.

Armstrong, D.J., McCausland, E.M., Wright, G.D., 2007. Hypertrophic pulmonary osteoarthropathy (HPOA) (Pierre Marie-Bamberger syndrome): two cases presenting as acute inflammatory arthritis. Description and review of the literature. Rheumatol. Int. 27, 399-402.

Assis, S., Santos, A.L., Roberts, C.A., 2011. Evidence of hyperotrophic ostearthropathy in individuals from the Coimbra Skeletal Identified Collection (Portugal). Int. J. Paleopathol. 1, 155-163.

Atkinson, M.K., McElwain, T.J., Peckham, M.J., Thomas, P.P., 1976. Hypertrophic pulmonary osteoarthropathy in Hodgkin's disease: reversal with chemotherapy. Cancer 38, 1729-1734.

Aufderheide, A.C., Rodriguez-Martín, C., 1998. Human Paleopathology. Cambridge University Press, Cambridge.

Bazar, K.A., Yun, A.J., Lee, P.Y., 2004. Hypertrophic osteoarthropathy may be a marker of underlying sympathetic bias. Med. Hypotheses 63, 357-361.
Cetinkaya, M.A., Yardimci, B., Yardimci, C., 2011. Hypertrophic osteopathy in a dog associated with intra-thoracic lesions: a case report and a review. Vet. Med. (Praha) 56, 595-601.

Christensen, T., Martínez-Lavín, M., Pineda, C., 2013. Periostitis and osteolysis in a medieval skeleton from South-West Hungary: (leprosy, treponematosis, tuberculosis or hypertrophic osteoarthropathy) a diagnostic challenge! Int. J. Osteoarchaeol. 23, 69-82.

De Boer, H.H., Van der Merwe, A.E., Maat, G.J.R., 2013. The diagnostic value of microscopy in dry bone palaeopathology: a review. Int. J. Paleopathol. 3, $113-121$.

Ferguson, N., Lévy, M., Ramos-Vara, J.A., Baird, D.K., Wu, C.C., 2008. Hypertrophic osteopathy associated with mycotic pneumonia in two juvenile elk (Cervus elaphus). J. Vet. Diagn. Invest. 20, 849-853.

Freyschmidt, J., 2001. Melorheostosis: a review of 23 cases. Eur. Radiol. 11, 474-479.

Golder, W., Wolf, K.J., 2001. CT-guided aspiration biopsy of infected aortic graft in a patient with hypertrophic osteoarthropathy. Saline injection to improve diagnostic yield-a case report. Acta Radiol. 42, 59-62.

González-Reimers, E., Trujillo-Mederos, A., Machado-Calvo, M., Castañeyra-Ruiz, M., Ordóñez, A.C., Arnay-de-la-Rosa, M., 2015. A skeletal case of hypertrophic osteoarthropathy from the Canary Islands dating from 1000 BP. Int. J. Paleopathol. 11, 1-6.

Graham, L.E., Parke, R.C., 2005. Melorheostosis-an unusual cause of amputation. Prosthet. Orthot. Int. 29, 83-86.

Guyot, H., Sandersen, C., Rollin, F., 2011. A case of hypertrophic osteoarthropathy in a Belgian blue cow. Can. Vet. J. 52, 1308-1311.

Headley, S.A., Ribeiro, E.A., Von, G., dos Santos, G.J., Bettini, C.M., Júnior, E.M., 2005. Canine hypertrophic osteopathy associated with extra-thoracic lesions. Ciênc. Rural 35, 941-944.

Jajic, Z., Jajic, I., Nemcic, T., 2001. Primary hypertrophic osteoarthropathy: clinical radiologic, and scintigraphic characteristics. Arch. Med. Res. 32, 136-142.

Kuhn, G., Schultz, M., Muller, R., Ruhli, F.J., 2007. Diagnostic value of micro-CT in comparison with histology in the qualitative assessment of historical human postcranial bone pathologies. HOMO 58, 97-115.

Latos-Bielenska, A., Marik, I., Kuklik, M., Materna-Kiryluk, A., Povysil, C., Kozlowsk, K., 2007. Pachydermoperiostosis-critical analysis with report of five unusual cases. Eur. J. Pediatr. 166, 1237-1243.

Lawler, D.F., Reetz, J.A., Sackman, J.E., Evans, R.H., Widga, C., 2015. Suspected hypertrophic osteopathy in an ancient canid: differential diagnosis of possible etiologies. Int. J. Paleopathol. 9, 52-58.

Lenehan, T.M., Fetter, A.W., 1985. Hypertrophic osteopathy. In: Newton, C.D., Nunamaker, D.M. (Eds.), Textbook of Small Animal Orthopedics. J.B. Lippincott Company, Baltimore, Consulted on 23 July, 2015 http://cal.vet.upenn.edu/ projects/saortho/chapter_51/51mast.htm.

Leri, A., Joanny, J., 1992. Une affection non decrite des os: hyperostose en coulge sur toute la hauteur d'un member ou mélorhéostose. Bull. Mém. Soc. Med. Hop. Paris 46, 1141-1145.

Mair, T.S., Tucker, R.L., 2004. Hypertrophic osteopathy (Marie's disease) in horses Equine Vet. J. 16, 308-311.

Martinez-Lavin, M., Mansilla, J., Pineda, C., Pijoan, C., Ochoa, P., 1994. Evidence of hypertrophic osteoarthropathy in human skeletal remains from Pre-Hispanic Mesoamerica. Ann. Intern. Med. 120, 238-241.

Masson, M., Molnár, E., Donoghue, H.D., Besra, G.S., Minnikin, D.E., Wu, H.H., Lee, O.Y., Bull, I.D., Pálfi, G., 2013. Osteological and biomolecular evidence of a 7000-year-old case of hypertrophic pulmonary osteopathy secondary to tuberculosis from neolithic hungary. PLoS One 8 (10), e78252.

Matos, V., Santos, A.L., 2006. On the trail of pulmonary tuberculosis based on rib lesions: results from the human identified skeletal collection from the Museu Bocage (Lisbon, Portugal). Am. J. Phys. Anthropol. 130, 190-200.

Mays, S., Taylor, G.M., 2002. Osteological and biomolecular study of two possible cases of hypertrophic osteoarthropathy from Mediaeval England. J. Archaeolog. Sci. 29, 1267-1276.

Ortner, D.J., 2003. Identification of Pathological Conditions in Human Skeletal Remains. Academic Press, Amsterdam.

Pálfi, G., Bereczki, Z., Ortner, D.J., Dutour, O., 2012. Juvenile cases of skeletal tuberculosis from the Terry Anatomical Collection (Smithsonian Institution Washington, D.C. USA). Acta Biol. Szegediensis 56, 1-12.

Resnick, M., Kransdorf, M.J., 2005. Bone and Joint Imaging. Elsevier Saunders, Philadelphia.

Roberts, C.A., Buikstra, J.E., 2003. The Bioarchaeology of Tuberculosis: A Global View on a Reemerging Disease. University Press of Florida, Gainesville.

Roberts, C.A., Boylston, A., Buckley, L., Chamberlain, A.C., Murphy, E.M., 1998. Rib lesions and tuberculosis: the palaeopathological evidence. Tuber. Lung Dis. 79, 55-60.

Roberts, C.A., Lucy, D., Manchester, K., 1994. Inflammatory lesions of ribs: an analysis of the Terry collection. Am. J. Phys. Anthropol. 95, 169-182.

Rothschild, B.M., Rothschild, C., 1998. Recognition of hypertrophic osteoarthropathy in skeletal remains. J. Rheumatol. 21, 2221-2227.

Santos, A.L., Gardner, M.T., Allsworth-Jones, P., 2013. Treponematosis in Pre-Columbian Jamaica: a biocultural approach to the human cranium found in Bull Savannah. J. Archaeol. Sci. 40, 490-496.

Santos, A.L., Roberts, C.A., 2006. Anatomy of a serial killer: differential diagnosis of tuberculosis based on rib lesions of adult individuals from the Coimbra identified skeletal collection, Portugal. Am. J. Phys. Anthropol. 130, 38-49.

Shih, W.J., 2004. Pulmonary hypertrophic osteoarthropathy and its resolution. Semin. Nucl. Med. 34, 159-163. 
Subhas, N., Sundaram, M., Bauer, T.W., Seitz, W.H., Recht, M.P., 2008. Glenoid labrum ossification and mechanical restriction of joint motion: extraosseous manifestations of melorheostosis. Skeletal Radiol. 37, 177-181.

Tran, H.A., 2004. Thyroid acropachy. Intern. Med. J. 34, 513-514.

Uppal, S., Diggle, C.P., Carr, I.M., Fishwick, C.W., Ahmed, M., Ibrahim, G.H., Helliwell, P.S., Latos-Bieleńska, A., Phillips, S.E., Markham, A.F., Bennett, C.P., Bonthron, D.T., 2008. Mutations in 15-hydroxyprostaglandin dehydrogenase cause primary hypertrophic osteoarthropathy. Nat. Genet. 40, 789-793.

Utine, E.G., Yalçin, B., Karnak, I., Kale, G., Yalçin, E., Doğru, D., Kiper, N., Akyüz, C., Büyükpamukçu, M., 2008. Childhood intrathoracic Hodgkin lymphoma with hypertrophic pulmonary osteoarthropathy: a case report and review of the literature. Eur. J. Pediatr. 167, 419-423.
Vandemergel, X., Blocklet, D., Decaux, G., 2004. Periostitis and hypertrophic osteoarthropathy: etiologies and bone scan patterns in 115 cases. Eur. J. Intern. Med. 15, 375-380.

von Hunnius, T., 2009. Using microscopy to improve a diagnosis: an isolated case of tuberculosis-induced hypertrophic osteopathy in archaeological dog remains. Int. J. Osteoarchaeol. 19, 397-405.

Wakely, J., Manchester, K., Roberts, C., 1991. Scanning electron microscopy of rib lesions. Int. J Osteoarchaeol. 1, 185-189.

Yao, Q., Altman, R.D., Brahn, E., 2009. Periostitis and hypertrophic pulmonary osteoarthropathy: report of 2 cases and review of the literature. Semin. Arthritis Rheum. 38, 458-466. 